\title{
Research on Steering Scheme of Long Semi-trailer
}

\author{
Xuwei Fang ${ }^{1,2}$, Xiaowei Fu' ${ }^{1,2, *}$, Jun Zhou ${ }^{1,2}$ and $\mathrm{Xi} \mathrm{Li}{ }^{3}$ \\ ${ }^{1}$ College of Computer Science and Technology,Wuhan University of Science and Technology, Wuhan, Hubei, China, 430065 \\ ${ }^{2}$ Hubei Province Key Laboratory of Intelligent Information Processing and Real-time Industrial System, Wuhan, Hubei, China, \\ 430065 \\ ${ }^{3}$ College of Automation, Huazhong University of Science and Technology, Wuhan, Hubei, China, 430074 \\ ${ }^{*}$ Corresponding author
}

\begin{abstract}
In the premise of meeting the kinematics, analyzing and optimizing the trafficability of long semi-trailer on the narrow road with obstacles on both sides. This paper gives a scheme by adjusting and designing wheelspan and wheelbase, which is proved the feasibility of the scheme by the experiment.
\end{abstract}

Keywords-long semi-trailer; ackerman steering; wheelspan; wheelbase

\section{INTRODUCTION}

There are a variety of transportation modes for the longdistance road transport. However, transporting by semi-trailer is the most economical way. The application of semi-trailer is wide, the applicability is also very strong, it will not only greatly improve transport efficiency and reduce transportation costs, fast turnover is a major feature of semi-trailer. In the completion of large, heavy parts and special cargo transport, small and medium-sized trucks can not be compared with it [1]. The longer the semi-trailer body, the larger the load, which can significantly reduce the transport, however, when the semi-trailer is simply lengthened, the minimum turning radius is greatly increased, and its passingability is seriously affected [2]. In this paper, there are obstacles on both the narrow road surface and the road surface, through the design of wheelspan and wheelbase, a steering scheme is proposed to meet the requirements of limit steering.

\section{SEMI-TRAILER STEERING}

Reference to the design of a universal semi-trailer, the size of a long semi-trailer is shown in Figure I. Trailers are required to pass on a narrow road with obstructions on both sides, which need the semi-trailer to do circular motion in Figure II, where the distance between 2 and 3 is road width, the distances between 1 and 4 is the sweep width of the semitrailer. The actual project problem can be described as the following mathematics problem. If the road width is K meters, the sweep width of the semi-trailer is not more than b1 meters, when the turning diameter is a1meters, the sweep width is not more than b2 meters when the turning diameter is a2 meters, and the sweep width is not more than b2 meters when the turning diameter is a3 meters, of which, $a 1<a 2<a 3, b 1>b 2>b 3$. Semi-trailer steering needs to meet the Ackerman steering principle [3]. when turning along a curve, the steering angle of the inner wheel is about 2-4 degrees So that the center of the four wheel paths intersect roughly at the instantaneous center of extension of the rear axle [4], allowing the vehicle to turn smoothly as shown in Figure III. In order to satisfy the above conditions, the purpose of this paper is to find a feasible solution [5-6].

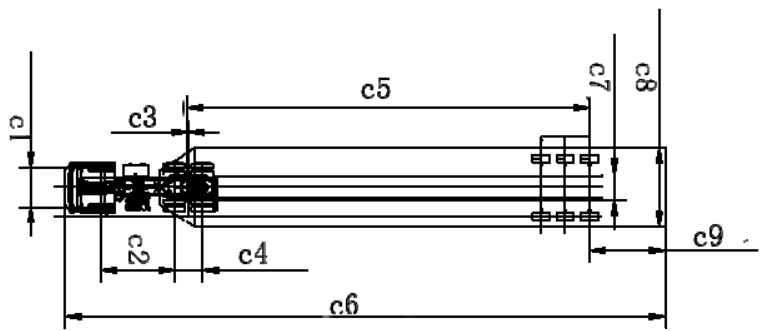

FIGURE I. SIZE OF SEMI-TRAILER

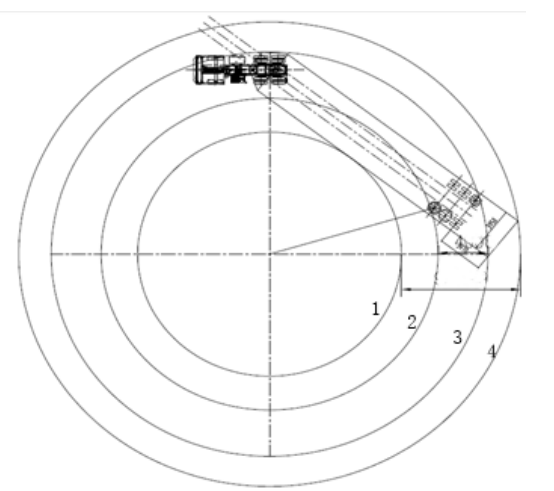

FIGURE II. RUN CONDITIONS OF SEMI-TRAILER

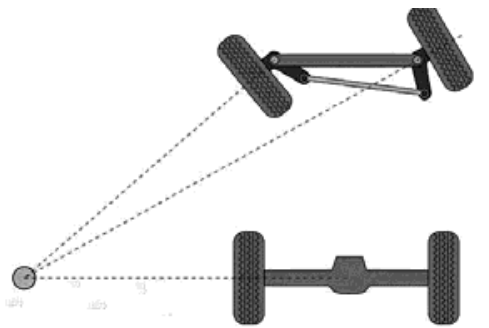

FIGURE III. THE SCHEMATIC DIAGRAM OF ACKERMAN TURNING

\section{TRAILER STEERING DESIGN}

\section{A. Limit turning Requires Calculation}

Assuming the semi-trailer tire steering angle is not greater than $\alpha$, and the diameter of tire is L1, the cross-sectional 
width of tire is L2, tire steering can not be obstruction with c7 (bar size)which in Figure I, the minimum track is calculated as follows:

$$
\begin{gathered}
L_{\text {min }}=\mathrm{c} 7+2 * \sqrt{\left(\frac{\mathrm{L} 1}{2}\right) \wedge 2+\left(\frac{L 2}{2}\right) \wedge 2} \\
*^{*} \cos \left(\arccos \left(\frac{L 2 / 2}{\sqrt{\left(\frac{L 1}{2}\right) \wedge 2+\left(\frac{L 2}{2}\right) \wedge 2}}\right)-\alpha\right)
\end{gathered}
$$

In order to prevent the tire from interfering with the side wheels during the steering process, there should be some margin between the two wheels. And because the two wheels are required to rotate during the interference does not occur, so the minimum wheelbase is calculated as follows:

$$
D_{\text {min }}=2 * \sqrt{\left(\frac{L 1}{2}\right) \wedge 2+\left(\frac{L 2}{2}\right) \wedge 2}+\delta
$$

Where $\delta$ is margin between the two wheels, it sets $\delta=10 \mathrm{~mm}$.

When the turning diameter is a3, the body sweeping width is no greater than b3, it is the most difficult to meet the limit turning conditions. So the exact calculation needs to be done to find a suitable overall trailer angle, the calculation method is as follows:

$$
\begin{gathered}
L_{\mathrm{o}}=\sqrt{\left(\sqrt{(\mathrm{a} 3)^{2}-\left(c 2+\frac{1}{2} * c 4\right)^{2}}-\left(\frac{c 1}{2}\right)\right)^{2}+(c 3)^{2}} \\
L_{p}=\sqrt{(c 5+c 9)^{2}+\left(\frac{c 8}{2}\right)^{2}} \\
\arccos \left(\frac{L_{o}^{2}+L_{p}^{2}-R_{\max }}{2 * L_{o} * L_{p}}\right)-\arccos \frac{c 5+c 9}{L_{p}} \\
=\arccos \frac{R_{\min }+\left(\frac{c 8}{2}\right)}{L_{o}}
\end{gathered}
$$

As shown in Figure I, $c 1$ is the wheelbase of tractor. $c 2$ is the distance between the center of the front and rear wheels. $c 3$ is the distance from connecting axis of the tractor and trailer to the center of tractor rear wheel. $c 4$ is rear wheel wheelbase. $c 5$ is the distance from the connecting axis to the last wheel of the trailer. $c 8$ is the width of trailer. $c 9$ is the distance from the last wheel of the trailer to the tail of trailer. $L_{o}$ is the distance from connecting axis to the turning center.
$L_{p}$ is the length of the transition line. As shown in Figure II, $R_{\min }$ is the radius of circle $1, R_{\max }$ is the radius of circle 4. $R_{\max }-R_{\min } \leq b 3$.

\section{EXPERIMENT}

The experiment is on the windows platform. Use MATLAB software to calculate, use CAD to draw simulation chart. According to the actual project requirements: the width of road is 4 meters, if the turning diameter is 35 meters, the sweep width of semi-trailer is not more than 10 meters, if the turning diameter is 40 meters, the sweep width of semi-trailer is not more than 9 meters , if the turning diameter is 45 meters, the sweep width of semi-trailer is not more than 8 meters. For turning diameter of 45 meters, it is difficult to meet the requirement that sweep width is less than 8 meters. Therefore, it is meaningful to find a suitable overall corner of the semitrailer by refined calculation. According to the size of semitrailer which is given from actual project in Fig.1 $\mathrm{c} 1=$ $1995 \mathrm{~mm}, \mathrm{c} 2=3650 \mathrm{~mm}, \mathrm{c} 3=45 \mathrm{~mm}, \mathrm{c} 4=1400 \mathrm{~mm}, \mathrm{c} 5=$ $20000 \mathrm{~mm}$, c8 $=3950 \mathrm{~mm}$, c9 $=3770 \mathrm{~mm}$, getting the formula 6 by substituting data into formula $3,4,5$ :

$$
\begin{aligned}
& \mathrm{L}_{o}=\sqrt{\left(\sqrt{22500^{2}-4350^{2}}-\left(\frac{1995}{2}\right)\right)^{2}+45^{2}} \\
& L_{p}=\sqrt{23770^{2}+\left(\frac{3950}{2}\right)^{2}} \\
& \arccos \left(\frac{L_{o}^{2}+L_{p}^{2}-R_{\max }}{2 * L_{o} * L_{p}}\right)-\arccos \frac{23770}{L_{p}} \\
& =\arccos \frac{R_{\min }+\left(\frac{3950}{2}\right)}{L_{o}}
\end{aligned}
$$

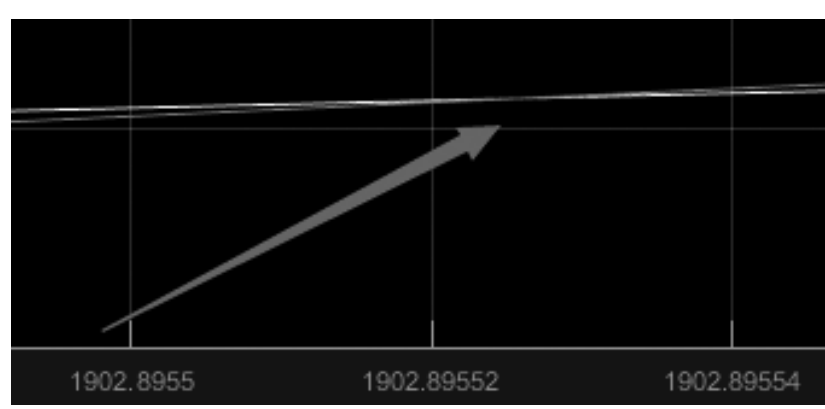

FIGURE IV. THE RESULT OF SIMULINK

Accord to formula (6), using traversal calculation method by MATLAB simulink, according to Figure IV, result is 22500 $+1902.8955=24402.8955 \mathrm{~mm}$, the result is the large circle radius of sweeping width. At the same time, the angle of the semi-trailer is 29.173 degrees.

If turning diameter is $45 \mathrm{~m}$, and the sweeping width need to be less than 8 meters, the angle of the tractor body and semi- 
trailer body need to be more than 29.66 degrees. Assuming that the steering angle is not greater than $45^{\circ}$, and the tire is selected for a solid tire with a diameter of $800 \mathrm{~mm}$ and a crosssectional width of $225 \mathrm{~mm}$, where c7 $=1300$ is calculated, getting the formula 7 by substituting data into formula 1,2 :

$$
\begin{aligned}
& L_{\min }=1320+2 * \sqrt{\left(\frac{800}{2}\right) \wedge 2+\left(\frac{225}{2}\right) \wedge 2} * \\
& \cos \left(\arccos \left(\frac{225 / 2}{\sqrt{\left(\frac{800}{2}\right) \wedge 2+\left(\frac{225}{2}\right) \wedge 2}}\right)-45^{\circ}\right)=2046 \mathrm{~mm} \\
& D_{\text {min }}=2 * \sqrt{\left(\frac{800}{2}\right) \wedge 2+\left(\frac{225}{2}\right) \wedge 2}+10 \approx 832+10=842 \mathrm{~mm}
\end{aligned}
$$

Getting the calculation results according to formula 7 . Using CAD to draw graphical representation of one - to - one ratio. At the turning diameter of 35 meters, when the wheelspan is selected to be the minimum of $2046 \mathrm{~mm}$ or the wheelbase is selected to be the minimum of $842 \mathrm{~mm}$, the arrangement of wheels 1-6 is as follows:

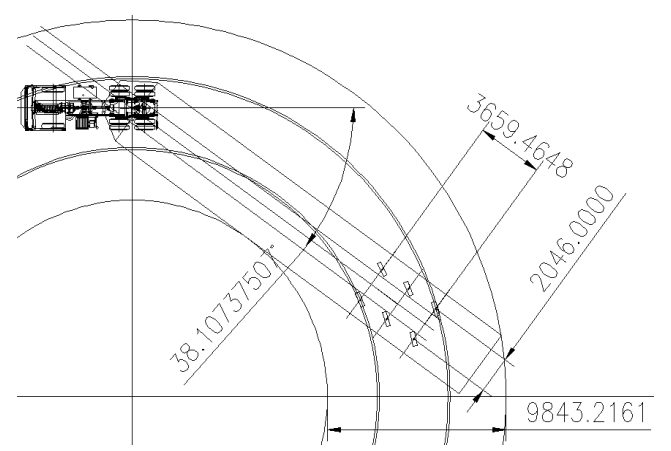

FIGURE V. THE MINIMUM OF WHEELSPAN FOR 35M

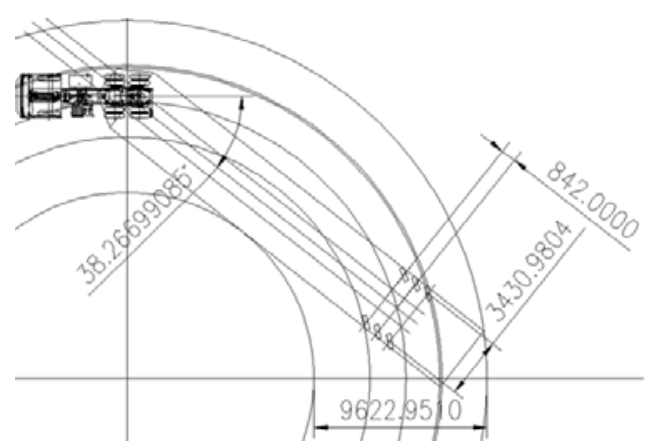

FIGURE VI. THE MINIMUM OF WHEELBASE FOR 35M

As can be seen in Figure V, the angle of tractor vehicle and semi-trailer reached 38.107 degrees. And the wheelbase has reached $1830 \mathrm{~mm}$, sweep width is $9843 \mathrm{~mm}$ which meet the requirements of less than 10 meters. As can be seen in Figure $\mathrm{VI}$, the tractor vehicle and semi-trailer angle reached 38.267 degrees. And wheelspan reached $3431 \mathrm{~mm}$. Sweep width is $9623 \mathrm{~mm}$ which meet the requirements of less than 10 meters.

At a turning diameter of $40 \mathrm{~m}$, when the wheelspan is selected to be a minimum of $2046 \mathrm{~mm}$ or the wheelbase is selected to be a minimum of $842 \mathrm{~mm}$, the arrangement of wheels 1-6 is as follows :

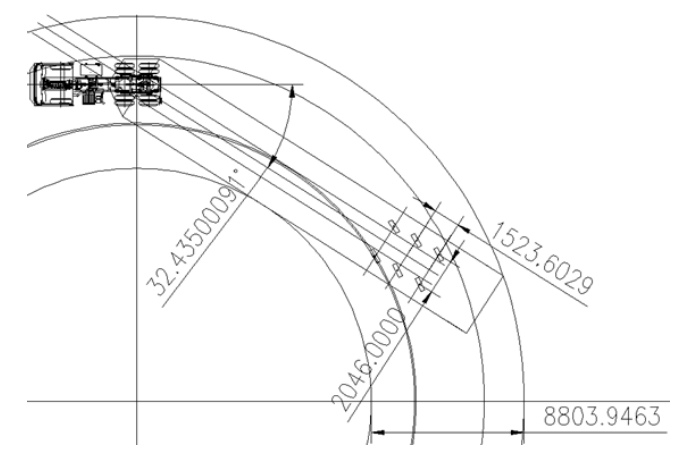

FIGURE VII. THE MINIMUM OF WHEELSPAN FOR 40M

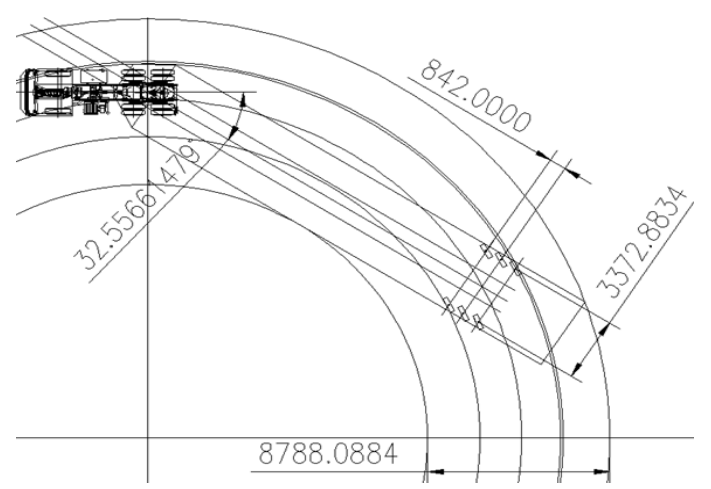

FIGURE VIII. THE MINIMUM OF WHEELBASE FOR 40M

It can be seen in Figure VII that the angle between tractor and semi-trailer reached 32.435 degrees. And the wheelbase has reached $1523 \mathrm{~mm}$. Body sweep width of $8803 \mathrm{~mm}$ which meet the requirements of less than 9 meters. As can be seen in Figure VIII, the angle between the tractor vehicle and the semi-trailer reached 32.557 degrees. And wheelspan reached $3373 \mathrm{~mm}$, Body sweep width is $8788 \mathrm{~mm}$ which meet the requirements of less than 9 meters.

At a turning diameter of $45 \mathrm{~m}$, when the wheelspan is selected to be a minimum of $2046 \mathrm{~mm}$ and the wheelbase is selected to be a minimum of $842 \mathrm{~mm}$, the layout of wheels 1-6 is shown in Figure IX and Figure $\mathrm{X}$ :

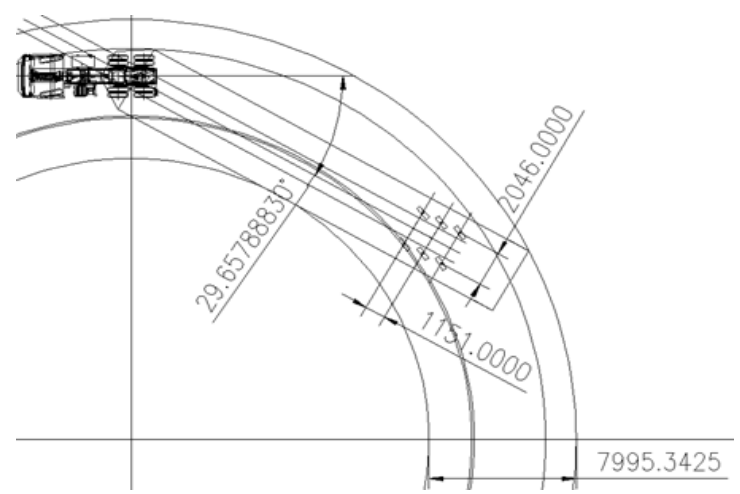

FIGURE IX. THE MINIMUM OF WHEELSPAN FOR 45M 


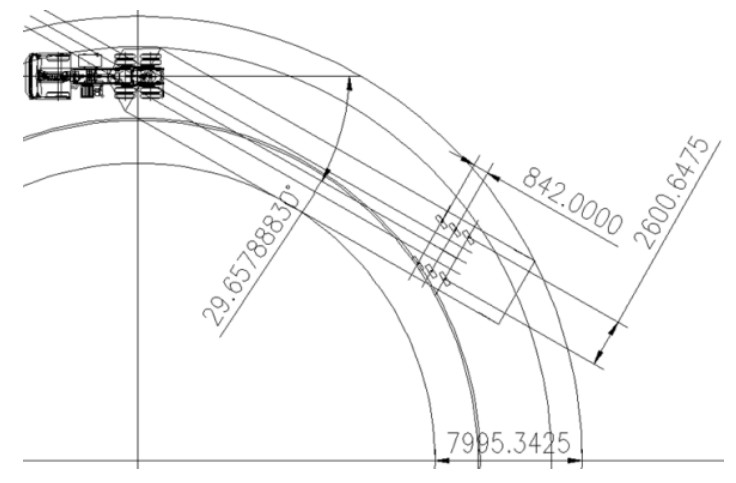

FIGURE X. THE MINIMUM OF WHEELBASE FOR 45M

It can be seen from Figure IX that the angle between tractor vehicle and semi-trailer reached 29.658 degrees. And the wheelbase has reached $1151 \mathrm{~mm}$. Body sweep width is $7995 \mathrm{~mm}$ which meet the requirements of less than 8 meters. As can be seen from Figure $X$, the angle between the tractor vehicle and the semi-trailer reached 32.557 degrees. And wheelspan reached $2601 \mathrm{~mm}$. Body sweep width is $7995 \mathrm{~mm}$ which meets the requirements of less than 8 meters.

The experimental results are as follows: When taking the minimum wheelbase, the results are shown in Table I. When taking the minimum track, the results are shown in Table II.

TABLE I. THE RESULT OF MINIMUM WHEELSPAN

\begin{tabular}{|c|c|c|c|}
\hline Turn diameter & Wheelbase & Included angle & Sweep width \\
\hline 35 & 3.431 & 38.267 & 9.623 \\
\hline 40 & 3.373 & 32.557 & 8.788 \\
\hline 45 & 2.601 & 29.658 & 7.995 \\
\hline
\end{tabular}

Unit: m

TABLE II. THE RESULT OF MINIMUM WHEELBASE

\begin{tabular}{|c|c|c|c|}
\hline Turn diameter & Wheelbase & Included angle & Sweep width \\
\hline 35 & 1.830 & 38.107 & 9.843 \\
\hline 40 & 1.523 & 32.435 & 8.803 \\
\hline 45 & 1.151 & 29.658 & 7.995 \\
\hline
\end{tabular}

Unit: m

For table I, it can conclude that when the wheels along the inner edge of the road and the wheelbase takes the minimum, for each turn diameter, when the angle and track satisfy the above requirements, the sweep width can be satisfied. For table II, it can conclude that when the wheels along the inner edge of the road and the wheelspan takes the minimum, for each turn diameter, when the angle and the wheelbase satisfy the above requirements, the sweep width can be satisfied.

\section{CONCLUSIONS}

This paper studies the steering of the over-long trailer on the narrow pavement with obstacles on both sides and proposes a set of practical design of the wheelspan and wheelbase of the semi-trailer, through simulate the steering of the trailer. The experimental results show the feasibility of this article design.

\section{ACKNOWLEDGMENT}

This work is partly supported by the open fund project of State key laboratory of Material Processing and Die \& Mould Technology (P2018-016), Hubei Provincial Natural Science Foundation of China (2017CFB506), the educational research project from the Educational Commission of Hubei Province (2016234), the open fund project of Hubei Province Key Laboratory of Intelligent Information Processing and Realtime Industrial System (2016znss02A) and the teaching research projects of Wuhan University Of Science and Technology Graduate Student Institute (Yjg201614, Yjg201613), the scientific and technological innovation project of Wuhan University Of Science And Technology (16ZRC084).

\section{REFERENCES}

[1] LIU Hai Liang. Research on the Status and Development Trend of Semi - trailer in China [J]. Heilongjiang Science and Technology Information, 09(2012), pp.114.

[2] ZHANG Lei, ZHANG Wen Ming. Optimization Design of the Steering Mechanism For the Long Semitrailer [J]. Hoisting and Conveying Machinery, 02(2006), pp.31-33.

[3] LI Hai Peng, SHI Bo Qiang, ZHANG Wen Ming. Design Methods and Its Program of Multi-Axle Trailer Steering Mechanism[J]. Journal of Tangshan College, 04(2005), pp.100-103.

[4] PEI Jin. Investigation and Emulation of Vehicle - Semitrailer System Turning Along Identical Locus Curve [J]. Special Purpose Vehicle, 02(1992), pp.6-11.

[5] Hayes D. Longer semi-trailer trial brings benefits[J]. Commercial Motor, 2013.

[6] Development W. Longer semi-trailer feasibility study and impact assessment: final summary report[J]. Heavy Vehicles, 2010. 